\title{
Discussion on the Role of Sustainable Sports Training in Talent Cultivation
}

\author{
You-yun ZHANG ${ }^{1, a,{ }^{*}}$ and Liang $\mathrm{ZU}^{2, \mathrm{~b}}$ \\ ${ }^{1}$ Chongqing Business Vocational College, china \\ ${ }^{2}$ Southwest University of Political science and Law, china \\ aILYM18@163.com, b40269500@qq.com \\ ${ }^{*}$ Corresponding author
}

Keywords: Sports training, Sustainable sports training, Talent cultivation.

\begin{abstract}
Sustainable sports training plays an important role in cultivating sports talent in improving competitive capability, digging out the potential quality, learning scientific and cultural knowledge and cultivating personal competency for sports talents.
\end{abstract}

\section{Introduction}

Sport training is generally adopted in the cultivation of professional athletes (also known as competitive sports talents). As an important part of sports professionals, professional athletes play a key role in the development of sports cause in China's universities and colleges. Now, the mode of "combination of physical and intellectual education" which emphasizes the equally important status of physical education and intellectual education is applied to the cultivation of professional athletes. For athletes, sport training is still an important channel to improve their competitiveness and comprehensive quality which is indispensable for the cultivation of professional athletes.

\section{A Probe into the Sustainability of Athletic Trainings}

\section{The Sustainability of Training Time}

The sustainability of training time means that the time necessary for athletic trainings should be consistently ensured during the pre-competition training periods. Regular training comes as the prioritized guarantee to desirable physical strength. Only by attending scheduled daily trainings are athletes able to maintain satisfactory athletic performance. The sustainability of training time is often associated with training schemes, which are scientifically developed based on specific trainings contents.

\section{The Sustainability of Training Intensity}

The sustainability of training intensity means that schemes should be made to increase the training intensity step by step to enhance the performance of athletes, according to the actual situation of athletes and the anticipated performance. Sustainable training intensity is indispensable to enhance athletic performance. The improvement in athletic performance is progressive. Training intensity is needed with the progress in athletic performance. However, the increase should follow a step-by-step process. 


\section{The Sustainability in Training Criteria}

The sustainability in athletic training standards means the criteria for assessing the athletic performance should be accordingly improved step by step. Stair-stepping athletic training criteria will also contribute to step-by-step progress in training goals for athletes. Athletic training criteria serve as the important guidance for trainings and also the most reasonable reference for the establishment of athletic training goals. Coaches will tailor athletic trainings goals based on the actual situation of athletes as well as the athletic training criterion. Athletic training criteria always progress gradually, such is also the case with athletic training goals.

\section{The Sustainability in Training Techniques}

The sustainability in training techniques means that, above all, it is necessary for athletes to have a command of basic training techniques. They will be then exposed to more training techniques with the progress in athletic training intensity and improvement in training criteria. The increasing intensity in athletic training will sustainably enhance the athletic training techniques. An important means to achieve the athletic training goals, athletic training technique constitutes an important part of physical education theories. Only by appropriate application of training techniques will athletes achieve twice training results with half the efforts.

\section{Analysis of the Role of Sustainable Sports Training in Talent Cultivation}

\section{The Role of Sustainable Sports Training in Improving the Competitive Capability of Sports Professionals}

The competitive capability of sports talent means athlete's capability in technique and strategy, his physical, mental and intellectual ability, etc. Emphasized in sports training, the competitive capability becomes the important factor to determine the value for the life of sports athlete. Technical capability means the ability of athlete to deal with the competitive match with his mastered sports skills and give a play of those skills in a flexible matter. Strategic capability means the ability of athlete to adjust his own sports route according to the actual situation in the match to take the advantageous position. Physical ability means the energy of athlete to deal with the match; the intelligence means the ability of athlete to wisely win the match after making adjustment upon analyzing his own state and the mental ability means athlete's psychological endurance.

Sustainable sport training is progressive in training time duration, increased strength, improved standard and technology, so as his competitive capability. The role of sustainable sports training in improving sports talent's competitive capability lies in persistent improvement of sports ability rather than broken development. For example, divers should firstly finish the movement in the lowest technical level and then the improved level guided by the coach along with more training. If they are trained with movement with higher technical level at the beginning, they must spend more energy and efforts to master the new technical movement and they may not master the technology without guaranteed training strength and duration. 


\section{The Role of Sustainable Sports Training in Digging out the Potential Quality of Sports Talent}

The potential quality refers to the sports talent's competitive capability to be further explored. As what is mentioned above, the competitive capability of sports athlete is including athlete's capability in technique and strategy, his physical, mental and intellectual ability, which are finally obtained in training for years. In training athlete, the coach concerns not only their current performance but also their competitive capability to be further explored. Technical potential means the ability to master sports movement in higher level physically and mentally. Strategic potential means the ability of athlete to accumulate more abundant strategic experiences in the daily training and matches. Physical, intellectual and mental potential means the ability of athlete to be improved in the above aspects through training.

Cultivation is such a process to dig out sports talent's potential quality which is reflected by excellent competitive skills. The rules and scientificity of sports training guarantee sustainable sports training to enable athletes to master visible competitive capability by improving the standard in constant physical training for years. As a scientific and reasonable principle, sustainable sports training has training level improved in a patient way to dig out their potential quality which could prevent stalled or spoiled competitive capability.

\section{The Role of Sustainable Sports Training in Sports Talent's Learning of the Scientific Culture}

The mode of "combination of physical and intellectual education" is applied in the cultivation of sports talents in China which focuses on both physical and intellectual training for sports talents. The scientific and cultural knowledge necessary for sports athlete to master is mainly including fundamental sports theory which is important to growth of sports talent and ideological and moral education of professional ethic and social ethic necessary to growth of sports talent which is the powerful guarantee to become a qualified talent. Physical and intellectual education has a mixed role on sports talent. Although it is within the scope of "physical education", sustainable sports training also plays a role in professional athlete's learning of scientific and cultural knowledge.

The sustainable sports training makes athletes initiatively study, overcome the difficulty until accomplish the scientific and cultural knowledge. Although trained in sports, athletes must pay unimaginable efforts under great pressure in sustainable sports training to become the outstanding talents. In sports training, they obtain the outstanding sports skills which subtly influence their personality available for use in developing in other fields. For example, Deng Yaping, the world table tennis champion, could still achieve the amazing results in learning the scientific and cultural knowledge after her sports career. The key reason is that she has cultivated perseverance quality in her sports career. In day-after-day training with increasing strength, rising standard and breaking technology, Deng Yaping's willpower has been cultivated that she is never afraid of any difficulty. It is also the most important reason that she is successful in learning the scientific and cultural knowledge. 


\section{The Role of Sustainable Sports Training In Cultivating Sports Talent's Character}

Sports talent's personal character means his intelligent level, personal charm and social behavior. After becoming sports talent, their personal character has also been enhanced. Among that, the intellectual level means the intelligence reflected in the enhancement of understanding, memory and imagination; personal charm means the attraction from others in behaving and getting along with people around them and social behavior means the influence of athlete's behavior on the society.

The scientifically demonstrated theory that sustainable sports training could enhance athlete's intellectual level is also widely used in promoting the sports in the public. It is often heard that people with sports have a quick response just because sports has greatly enhanced their response ability. The persistence, efforts and struggling demonstrated in sports training also deserve the admiration from people which have been involved into athlete's heart in long-term sports training and become their charming personality. Athletes also have strong social responsibility that they make efforts to realize their own value for a higher competitive level and drive further development of the competitive sports. In participating sports match, they consider more to win the honor for the group and their motherland and such strong social responsibility inspires everyone around them.

\section{References}

[1] Huo Hong. Research of personality feature of students in different speciality in sports college and its evaluation [J]. Journal of Chengdu Physical Education Institute. 2014 (2) In Chinese

[2] Zou Xuan. Analysis of application of sports psychology in sports training and match [J]. New Couse: Teacher. 2014 (2) In Chinese

[3] Wang Jianmin. Opinion on application of modern sports mean in sports training [J]. New West: Late • Theory. 2014(3) In Chinese 